\title{
Oral Communication in an Integrated STEM and Humanities First-Year Experience
}

\author{
Derek Sherman, Tejasvi Parupudi, Nathan Mentzer, Amelia Chesley, \\ Dawn Laux, \& Sweta Baniya
}

\begin{abstract}
This study looks at Purdue University's Integrated First-Year Experience of Design Thinking in Technology, Fundamentals of Speech Communication, and First-Year Composition and its effects on oral communication. We examined whether this three-course integration inspired by writing-across-the-curriculum and communication-across-the-curriculum would lead students to develop more effective oral communication skills than a nonintegrated course. Frameworks for 21 st century skills and the National Association of Colleges and Employers (2017) have pinpointed the importance of oral and written communication skills and initiatives. Still, research has produced mixed results on how well universities are preparing students for the workplace. Our study investigated whether the integrated program had better end-of-semester group oral presentations than student groups enrolled only in our Design Thinking in Technology course. A quasi-experimental design and post-only analysis revealed that integrated sections had more effective oral presentations than the nonintegrated sections.
\end{abstract}

Keywords: First-year integration, oral communication, communication across the curriculum, transfer, 21 st century skills frameworks

\section{Introduction}

Research indicates that formal course integration can improve student learning across disciplines. Often, institutional efforts to support interdisciplinary, integrated pedagogy are seeking to address specific skills gaps. For example, researchers have recognized a significant disparity between employers' expectations and graduates' demonstrated communication skills, empathy and audience awareness, and critical thinking abilities (Liu et al., 2014; Radermacher et al., 2014). Multiple research angles have indicated that interdisciplinary pedagogical integration may improve student learning experiences and enhance students' likelihood of transferring strong oral communication skills (Bannerot et al., 2010; Brizee \& Langmead, 2014; Morton \& O'Brien, 2005; Paretti, 2008). Furthermore, 21st century skills frameworks

Sherman, D., Parupudi, T., Mentzer, N., Chesley, A., Laux, D., \& Baniya, S. (2020). Oral communication in an integrated STEM and humanities first-year experience. Journal of Technology Education, 32(1), 50-64. https://doi.org/10.21061/jte.v32i1.a.4 
(e.g., ABET, 2014) have provided guidance in addressing skills that prepare students for future coursework and the workplace. There remain, however, many unanswered questions about the effectiveness of interdisciplinary integration, particularly in terms of its impact on oral communications. This research investigated the effectiveness of one interdisciplinary integration on oral communication development through a writing-across-the-curriculum and communication-across-the-curriculum framework effort at Purdue University.

Practices in writing-across-the-curriculum (WAC) and communicationacross-the-curriculum (CAC) inspired our work as we proposed an integrated framework in partnership with Purdue's Lamb School of Communication, Department of English, and Polytechnic Institute. Sharing similar goals and outcomes, WAC and CAC practices "have come together in a more strategically collaborative manner - in research and practice" (Dannels \& Housley Gaffney, 2009, p. 126). WAC/CAC frameworks advocate practices that mimic the disciplinary or workplace situations that students may experience in their future coursework and careers while attempting to address the various 21 st century skills frameworks' deficiencies described by Jang (2016).

Our previous integrated research (Chesley et al., 2018) combined written and oral communication in the context of real-life problem-solving in a Design Thinking in Technology course. Within the present study, we focused on the oral communication skills of student teams. We suggested that the communicative and integrated elements of First-Year Composition, Fundamentals of Speech Communication, and Design Thinking in Technology coalesce to provide students with a greater opportunity to develop essential oral communication skills that employers seek from graduates.

First, we illustrate how 21 st century skills frameworks are informative yet deficient in terms of their use. Next, we discuss the potential that active learning pedagogies and $\mathrm{WAC} / \mathrm{CAC}$ practices have in addressing these deficiencies. Last, we describe Purdue University's first-year integrated experience and consider evidence that it fosters oral communication skills.

The Need for Verbal Communication: Existing Frameworks and Implementation

Students in STEM must gain 21st century skills to succeed in a competitive world. Results from a Gallop Poll (as cited in Sidhu \& Calderon, 2014), however, suggested that only $11 \%$ of business leaders believed that higher education institutions are effectively preparing graduates with skills and competencies aligned with workforce needs. On the other hand, $96 \%$ of chief academic officers believed that graduates are career-ready. Universities should mend this stark misalignment through better skill-building initiatives such as implementing 21st century skills frameworks.

Various frameworks characterize important workplace skills, such as the Framework for 21 st Century Learning that was crafted around the 4Cs: 
communication, collaboration, creativity, and critical thinking (Trilling \& Fadel, 2009). The importance of oral and written communication skills was also emphasized by the National Association of Colleges and Employers (2017).

Working with the Occupational Information Network, Jang's (2016) analysis found that the five highest-rated skills for 21st century learning were: (a) "critical thinking," (b) "reading comprehension," (c) "active listening," (d) "speaking," and (e) "complex problem-solving" (p. 291). Additionally, the most important work activities included: (a) "getting information," (b) "making decisions and solving problems," (c) "interacting with computers," (d) "communicating with supervisors, peers, or subordinates," and (e) "updating and using relevant knowledge" (p. 291). It is important that universities acknowledge these workplace skills and activities and for frameworks to incorporate them within their standards.

However, Jang (2016) suggested that each framework has deficiencies. For example, Jang argued that ABET's engineering criteria for 2015-2016 have shortcomings in the "domains of working with an organizational system, illdefined problem solving, and time, resource, and knowledge management" ( $p$. 295). How do institutions that adopt this framework intend to address this deficiency and its relationships to oral and written communication? Lucas (2019) argued that "Expansive education, learning power and new pedagogies for deeper learning all shift the debate away from the what to the how of learning, focusing at least as much attention on pedagogy as on skills or capabilities or dispositions" (p. 15). Therefore, university programs should push the conversation toward pedagogy.

\section{Combining Active Learning With Writing and Communication Initiatives}

Although some frameworks may be complementary to 21st century skills, they can lack clarity on how to incorporate workplace skills in STEM curricula. Freeman et al. (2014) showed that active learning in STEM disciplines improves student performance, as evidenced by higher examination scores and reduced failure rates than traditional lecturing. Active learning involves in-class discussions and activities with teamwork as intrinsic components, making it different from traditional lecturing. A 21st century curriculum must be conducive toward active learning because it is necessary for students to demonstrate the ability to work in cross-functional and diverse teams. Chi (2009) suggested that curricula should include interactive learning or activities that incorporate instructional and joint dialogues (i.e., consultations with experts and peers on projects and activities.) Interactive learning that employs instructional and joint dialogues creates a shared understanding among collaborators from which new conceptions may emerge (p. 87).

Potentially, WAC models may serve as an intervention for addressing the deficiencies of 21 st century skills frameworks. Writing to learn and writing in the disciplines, sometimes referred to as writing to communicate, are the two 
guiding practices of WAC. McLeod (2012) argued that writing to learn "encourages teachers to use writing as a tool for learning as well as a test for learning" (p. 151). Writing to learn is usually an informal and ungraded approach to writing, including activities such as journals, annotations, and response papers (WAC Clearinghouse, 2019a).

On the other hand, writing in the disciplines uses the language practices of a particular domain and goes beyond the self as the audience (McLeod, 2012, p. 153). Activities for writing in the disciplines are more formal and require students to write in the genres and styles of a particular discipline, including project proposals, journal articles, and other works. (WAC Clearinghouse, 2019b). Bazerman (1992) argued that WAC helps students to "use them [disciplinary languages] more effectively as individuals and as members of the disciplinary groups" (p. 1847).

Like WAC, CAC relies on two principles: that "communication is too important to be taught in a single course, and that learning occurs best through the cognitive processes associated with message formation" (Steinfatt, 1986, p. 464). Central to both WAC and CAC is communication in a particular discourse community. For an oral communication model, Dannels (2001) proposed four "theoretical principles: 1) oral genres are sites for disciplinary learning[,] 2) oral argument is a situated practice, 3) communication competence is locally negotiated, and 4) learning to communicate is a context driven activity" (p. 147). Communication courses that build in these four theoretical principles alongside STEM-based frameworks for 21st-century learning while supplementing student learning with active learning pedagogy may be more effective.

\section{The Instructor's Role in Frameworks}

Successful application of the 21 st century skills framework relies heavily on the instructor's role and goals for the course. Paretti (2008) stated that faculty must have a strategy in the classroom to help students understand the functions of the assignments by relating them to professional contexts. Winsor's (1996) Writing Like an Engineer: A Rhetorical Education, for example, provided insight into how workplace communication, writing, and classroom frameworks create a professional context for the four students she interviewed. Winsor's discussion focused on four areas: the socialization of engineering students, audience issues, relationships between text and reality, and students' selfvisualization as engineers. Winsor's work recognized the role that the instructor plays in socializing students into the discourse community — groups who share similar values and methods of communication-although this is not her focus. It is the instructor's responsibility to create a classroom context and activities that support workplace and discourse community communication because this exposure allows students to become active members of that discourse community. Dannels' (2001) four theoretical principles for communication and Winsor's (1996) four areas of focus provide instructors with a basis for 
developing a classroom climate that focuses on oral communication within a discourse community.

Conrad's (2017) study further suggested that communication courses in the disciplines require specific teaching strategies. Three teaching implications were born out of Conrad's research: (a) "engineering faculty need to be responsible for teaching discipline-specific writing skills in their courses" (p. 210), (b) instructors and students should analyze samples of effective practitioners' writing (p. 210), and (c) feedback needs to pinpoint "that inaccurate, ambiguous, or error-ridden sentences are as problematic for engineering as inaccurate, ambiguous, or error-ridden calculations" (p. 211). Instructors who are members of the discourse community are better prepared to create authentic activities, introduce written and oral communication examples, and provide relevant feedback.

\section{First-Year Integration Programs and Their Role}

The American Society for Engineering Education's Committee on Evaluation of Engineering Education (1955/1994) report, known as the Grinter Report, called for an effort to integrate work in the humanities into STEM programs, which a WAC/CAC framework offers. One pivotal goal for integrated courses, as stated by the Committee on Integrated STEM Education, is improving 21st-century skills among students (Honey et al., 2014, p. 32), and thereby potentially improving conceptual learning (p. 52). First-year seminar courses, residential and academic learning communities, and various forms of course integration are common strategies for increasing student engagement, retention, and overall academic success.

Scholars in many disciplines have investigated various types of integration and other first-year programs, initiatives, and techniques (e.g., Bannerot et al., 2010; Paretti, 2008). Some of these involved institutions' writing centers and writing in the disciplines programs. Other course integrations were driven by cross-disciplinary collaborations and initiatives. CAC frameworks have fostered oral communication in fields such as business (Jankovich \& Powell, 1997), animal science (Orr, 1996), design education (Morton \& O'Brien, 2005), engineering (Dannels, 2002), and theatre and education (Friedland, 2004). For example, in a 2002 study about a CAC framework, Dannels found that "Learning to speak like an engineer was not just about negating filler words or nervous gestures, but rather about the complex ways orality was tied to the situated values, norms, and audiences of engineering" (p. 266).

Northwestern University integrated design thinking with communication in a freshman-level program (Colgate et al., 2004). The Design Thinking \& Communication courses were cotaught by engineering and writing faculty, and students worked in teams to address projects submitted by actual clients (Northwestern University, 2019b). This course required students meet five objectives: (a) "study a problem from multiple perspectives"; (b) "learn how to 
frame the design challenge properly"; (c) "ideate, prototype, and iterate solutions"; (d) "communicate their ideas clearly in design reviews, reports, and presentations"; and (e) "learn from the overall design process how to create value, prepare for their careers, and participate more fully in society" (Northwestern University, 2019a). The course utilized active pedagogy, communication, and real-world problems to address workplace skills.

\section{The Integrated First-Year Experience Program}

This study took place at Purdue University, a public university in the Midwestern United States with an undergraduate enrollment of more than 30,000 students. The study was situated within the Integrated First-Year Experience program, which aimed to provide realistic problem-solving scenarios that would enhance students' design thinking and oral communication. By connecting the curriculum across disciplines and university colleges, educators expected to see measurable improvements in the composition, communication, and critical thinking habits of students in all technology majors. The principles and practices of WAC/CAC and integrated pedagogy across the humanities and STEM courses are well-suited for these goals and offer opportunities to increase students' effectiveness in and preparedness for workplace communications.

The program brings together three required introductory courses at Purdue University: First-Year Composition, Fundamentals of Speech Communication, and Design Thinking in Technology. The general education curriculum requires all students to take First-Year Composition and Fundamentals of Speech Communication. Design Thinking in Technology is a core requirement for all students in Purdue's Polytechnic Institute.

Students in Design Thinking in Technology grapple with complex problems affecting our planet and use the design process to research, develop, and propose innovative, realistic solutions to those problems. Although critical thinking is a more common term related to the most crucial skills needed by college graduates, the term design thinking has entered discussions to reflect a more active, solution-oriented mindset. Design thinking encompasses the strategic, practical, situated processes of conceiving and actualizing new, innovative solutions to problems using iteration and testing. By the end of their semester of Design Thinking in Technology, students should have developed the crucial values of teamwork and ethical, human-centered design.

Community and teamwork are also important active-learning elements of the integrated courses. Fundamentals of Speech Communication gives students opportunities to practice and improve their oral communication skills, including interpersonal communication and collaboration in small groups. Students plan and present informative and persuasive speeches individually and in teams. In First-Year Composition, students analyze, critique, and practice creating their own written and multimodal compositions. Students also compose texts in multiple media and modes, review and revise their own and their peers' 
compositions, and practice performing research and analysis using diverse sources.

In this integrated program, each Design Thinking in Technology section functions as a central point in a trio of integrated courses and serves as the discourse community studied. A student enrolled in the Integrated First-Year Experience will spend time with a group of the same 20-25 students enrolled in Design Thinking in Technology and First-Year Composition or in Design Thinking in Technology and Fundamentals of Speech Communication.

Instructors in Design Thinking in Technology worked with English and communication instructors to collaboratively explore and implement ways of connecting and reinforcing the curriculum in their courses. The partnerships among the three disciplines aimed to foster improvement in students' composition, writing, oral presentation, and design-thinking skills. The instructors agreed to a set of extra teaching expectations for a small stipend, including the following.

1. Instructors participated in a 2-hour orientation workshop prior to the semester. Instructors engaged in coteaching dialogs to establish relationships within their trios.

2. Instructors met weekly for at least ten meetings during the semester to coplan:

i. Major student deliverables,

ii. Continuity of instruction between trio members,

iii. How student teams will be formed, and

iv. Details of the integrated projects.

3. Instructors cotaught on four occasions (minimum):

i. The first week of class to introduce what the integration means for students,

ii. Any time during the semester at the intersection of the three disciplines,

iii. Introduction of the final project, and

iv. Final project presentations.

Our program used the following process for course development: (a) consult 21 st century frameworks and use WAC/CAC practices to address the lack of clarity in oral and written communication skills, (b) design a course in which instructors use WAC/CAC practices and design thinking, and (c) implement active pedagogy, including collaboration and instructional and joint dialogues, as suggested by Chi (2009). 


\section{Methods}

Our priority for this study was to learn whether the integration described here helped students demonstrate stronger oral presentation skills. The following research question guided this study: "Do technology student teams who take an integrated design course deliver higher quality presentations than those who do not?" The data collected and analyzed included final project presentations from integrated and nonintegrated sections of the Design Thinking in Technology courses during the fall 2016 semester.

We employed a quasi-experimental design and post-only analysis to investigate the effects of the described integration and compared the results with the nonintegrated sections. Because students self-enrolled in sections of Design Thinking in Technology, we cannot assume that students were similar across sections regarding key variables. However, we assumed that student groups were similar enough to warrant this study design. Also, we did not determine whether individual students delivered more effective presentations based on their integration or nonintegration status. Rather, we assessed groups of students and their collaborative ability to demonstrate effective communication skills.

\section{Implementation and Data Collection}

Technology and communication instructors introduced the final design project to the integrated sections. Instructors explained the purpose of the integrated project, as well as the purpose of the in-class presentation. Instructors emphasized that the collaborative team presentation should meet two goals: the presentation should persuade their audience to support their design recommendations (i.e., their solution), and it should convincingly demonstrate that the students have done their due diligence in developing a solution by following a structured and valid process.

Instructors provided comparable directions to students in the nonintegrated sections of Design Thinking in Technology with a few differences. Instructors stipulated that presentations should be 5 minutes in length with an additional 2 3 minutes for questions and answers. Nonintegrated sections had a shortened length requirement because of time constraints. In both integrated and nonintegrated sections, instructors expected each team member to play an active role in the presentation.

At the end of the 8-week final project, the final presentations of student teams were video recorded by the instructor and shared at the conclusion of the semester. The research team screened a total of 100 video recordings and eliminated 16 recordings for which adequate analysis was not possible due to the poor quality of the image or audio. After screening, the sample consisted of 82 presentations, 35 from the integrated sections and 47 from the nonintegrated sections. 


\section{Data Analysis}

Instructors of the integrated sections adapted a rubric based on criteria from Morgan and Natt's (2013) Effective Presentations' "Speech Evaluation Form A: Persuasive Presentations" (p. A63). These criteria are shown in Table 1. The only change instructors made included the addition of criterion from the text's "Outline Checklist: Persuasive Presentation" (p. A57) that suggested the "use of a variety of supporting materials." Course instructors of both the integrated and nonintegrated sections assessed students' presentations with this rubric.

Table 1

Criteria for Pursuasive Presentations

\begin{tabular}{|c|c|c|}
\hline Introduction & Body & Conclusion \\
\hline $\begin{array}{l}\text { - Captured attention } \\
\text { - Stated thesis } \\
\text { - Related topic to } \\
\text { audience } \\
\text { - Established } \\
\text { speaker credibility } \\
\text { - Previewed main } \\
\text { points } \\
\text { - Provided } \\
\text { transition to body } \\
\text { while introducing } \\
\text { speakers }\end{array}$ & $\begin{array}{l}\text { - Organized main points } \\
\text { clearly and logically (clearly } \\
\text { outlining innovation/solution } \\
\mathbf{1} \text { and 2) } \\
\text { - Included transition between } \\
\text { main points } \\
\text { - Used accurate, relevant, and } \\
\text { timely supporting materials in } \\
\text { sufficient quantity } \\
\text { - Used a variety of supporting } \\
\text { material (statistics, examples, } \\
\text { narratives) } \\
\text { - Cited sources accurately in } \\
\text { speech } \\
\text { - Used well-reasoned arguments } \\
\text { - Avoided logical fallacies } \\
\text { - Used persuasive language }\end{array}$ & $\begin{array}{ll}\text { - } & \text { Provided } \\
\text { transition to } \\
\text { conclusion } \\
\text { - } & \text { Restated } \\
\text { thesis } \\
\text { - Summarized } \\
\text { main points } \\
\text { - Ended with a } \\
\text { memorable } \\
\text { final thought } \\
\text { (clincher) }\end{array}$ \\
\hline
\end{tabular}

Note. Adopted from Morgan, M., \& Natt, J. (2013). Effective presentations (3rd ed.) (p. A63). Cengage.

The rubric's criteria were validated through its 10 years of use in Purdue's School of Communication, with approximately 200 sections offered per year and 20-24 students in each section. Student performance for each of the 18 criteria in Table 1 was assessed using a Likert-based scale $(1=$ Unacceptable; Criteria is absent to $5=$ Excellent; Criteria meets or exceeds expectations and meets major audience expectations). The total scores possible ranged from 18 to 90. Instructors also provided students with a "Course Standards and Philosophy" 
statement in their Fundamentals of Speech Communication syllabus that conformed to the rubric's evaluative remarks.

A trained communications instructor on the research team mentored two graduate student researchers to use the Persuasive Presentation rubric to analyze the final sample of presentation videos. To develop consistent ratings among evaluators, these graduate student researchers engaged in three consecutive rounds of review, discussion, and negotiation. A Cronbach's alpha value of 0.889 between the raters indicated a good level of consistency (Santos, 1999) on sixteen presentations, $20 \%$ of the data. After a good level of consistency was achieved, one researcher evaluated all 82 blinded presentation videos, noting the average scores for presentations in both the integrated and nonintegrated sections.

\section{Results}

A Levene's Test for Equality of Variances revealed that the scores for presentations in both the integrated and nonintegrated sections were homogenous $(p>.05)$. Therefore, an independent samples $t$-test was run for mean difference between the groups at a $95 \%$ confidence interval. A significant difference existed in the scores for the integrated $(\mathrm{M}=62.40, S D=9.65)$ and non-integrated $(\mathrm{M}=48.06, S D=9.359)$ sections; $t(-6.771)=80, p<.001$. The mean difference between the integrated and nonintegrated sections was 14 points, representing a difference of approximately 15 percentage points. These results suggest that student groups in the integrated version of the course have developed significantly stronger communication skills than students who take the courses separately.

\section{Discussion}

At the end of their 8-week final project, students in the integrated versions of Design Thinking in Technology and Fundamentals of Speech Communication showed presentation scores $15 \%$ higher than scores in the nonintegrated courses. A $15 \%$ difference is both statistically and practically significant because it represents a difference of about one and one-half letter grades.

Nowacek's (2011) research on transfer showed that integrated models in which instructors communicate with each other regularly might foster transfer more readily. We theorize that students in the integrated sections approached the final presentations for their design projects with better preparation in using communication skills, transferring knowledge and practices from Fundamentals of Speech Communication to Design Thinking in Technology. Students in integrated sections may have obtained a deeper understanding of the design project because of the expansive frame (Engle et al., 2012) and the explicit connections that instructors created between design thinking and communication. Activities within individual classrooms and shared activities between courses may have further propelled the integrated group's success. 
Instructors in both courses, Design Thinking in Technology and Fundamentals of Speech Communication, referenced each other's course, and encouraged students to make connections between courses. Students in the nonintegrated sections did not have this consistent referral to other classes.

Given the quasi-experimental nature of this study, several other factors may explain the differences between comparison groups. The comparison groups consisted of intact sections of a course; there was no selection or assignment to treatment conditions. Data were not gathered to enable the assessment and control of preexisting characteristics of students and groups or the possibility that students were concurrently enrolled in a nonintegrated Fundamentals of Speech course. There were different time limits for presentations, and the instruction may not have been consistent for comparison groups. However, five of the six instructors involved in this study taught both integrated and nonintegrated sections, which enhanced the consistency of the treatment.

\section{Future Research}

We plan to continue our investigation of implementing WAC and CAC principles into first-year experience courses, especially in terms of promoting transfer via expansive frames, explicit skill teaching, and relationship to students' future careers. Future research should seek to confirm the results of the current study by employing a more rigorous research design that helps control for alternative explanations of learning transfer. We will examine more closely the pedagogical and collaborative integration between only two courses by analyzing subcomponent scores of the Persuasive Presentation rubric. Such a breakdown of scores could provide insights into areas that may need further pedagogical support. Additionally, future research could study written communication differences between integrated and nonintegrated sections.

\section{Conclusion}

In conclusion, this quasi-experimental study examined the end-of-semester presentation skills of student groups in integrated and nonintegrated sections of a college freshman level Design Thinking in Technology course. A programsupported pedagogical approach within the integrated sections required instructors to meet and collaborate on the final project and apply WAC/CAC principles; therefore, these results demonstrate the potential benefits that expansive frames and explicit skill teaching may have on students' abilities to transfer oral communication skills. Students in the nonintegrated groups may or may not have had a communication or composition course. If they had, it was unrelated to their design course, so transfer may have been more difficult for these students. Because students in the integrated courses scored significantly higher on their presentation than students in the nonintegrated sections, we will continue to offer integrated sections to foster student learning and transfer as resources permit. 


\section{References}

ABET. (2014). Criteria for accrediting engineering programs: Effective for reviews during the 2015-2016 accreditation cycle. https:/www.abet.org/wp-content/uploads/2015/05/E001-15-16-EACCriteria-03-10-15.pdf

American Society for Engineering Education, Committee on Evaluation of Engineering Education. (1994). Summary of the report on evaluation of engineering education. Journal of Engineering Education, 83(1), 74-93. https://www.asee.org/papers-and-publications/publications/The-GrinterReport-PDF.pdf (Reprinted from "Summary of the report on evaluation of engineering education," 1955, Journal of Engineering Education, 46[1], 25-60.)

Bannerot, R., Kastor, R., \& Ruchhoeft, P. (2010). Multidisciplinary capstone design at the University of Houston. Advances in Engineering Education, 2(1), Article 4. https://advances.asee.org/wpcontent/uploads/vol02/issue01/papers/aee-vol02-issue01-p04.pdf

Bazerman, C. (1992). Linguistic and rhetorical studies. In B. R. Clark \& G. R. Neave (Eds.), Encyclopedia of higher education: Volume 3: Analytical perspectives (pp. 1847-1852). Pergamon Press.

Brizee, A., \& Langmead, J. (2014). Cross-disciplinary collaboration: Fostering professional communication skills in a graduate accounting certificate program. Across the Disciplines, 11(1).

http://wac.colostate.edu/atd/articles/brizee_langmead2014.cfm

Chesley, A., Coots, M. W., Jackson, A., Knapp, S., Mentzer, N., \& Laux, D.

(2018). The impacts of integrating introductory composition, communication, and design thinking courses. Journal of Technology Education, 30(1), 66-82. https://doi.org/10.21061/jte.v30i1.a.4

Chi, M. T. H. (2009). Active-constructive-interactive: A conceptual framework for differentiating learning activities. Topics in Cognitive Science, 1(1), 73105. https://doi.org/10.1111/j.1756-8765.2008.01005.x

Colgate, J. E., McKenna, A., \& Ankenman, B. (2004). IDEA: Implementing design throughout the curriculum at Northwestern. International Journal of Engineering Education, 20(3), 405-411. https://www.ijee.ie/articles/Vol203/IJEE2505.pdf

Conrad, S. (2017). A comparison of practitioner and student writing in civil engineering. Journal of Engineering Education, 106(2), 191-217. https://doi.org/10.1002/jee.20161

Dannels, D. P. (2001). Time to speak up: A theoretical framework of situated pedagogy and practice for communication across the curriculum. Communication Education, 50(2), 144-158. https://doi.org/10.1080/03634520109379240 
Dannels, D. P. (2002). Communication across the curriculum and in the disciplines: Speaking in engineering. Communication Education, 51(3), 254-268. https://doi.org/10.1080/03634520216513

Dannels, D. P., \& Housley Gaffney, A. L. (2009). Communication across the curriculum and in the disciplines: A call for scholarly cross-curricular advocacy. Communication Education, 58(1), 124-153. https://doi.org/10.1080/03634520802527288

Engle, R. A., Lam, D. P., Meyer, X. S., \& Nix, S. E. (2012). How does expansive framing promote transfer? Several proposed explanations and a research agenda for investigating them. Educational Psychologist, 47(3), 215-231. https://doi.org/10.1080/00461520.2012.695678

Freeman, S., Eddy, S. L., McDonough, M., Smith, M. K., Okoroafor, N., Jordt, H., \& Wenderoth, M. P. (2014). Active learning increases student performance in science, engineering, and mathematics. Proceedings of the National Academy of Sciences, 111(23), 8410-8415.

https://doi.org/10.1073/pnas.1319030111

Friedland, E. (2004). Oral communication across the curriculum: What's a small college to do? Report of a collaborative pilot by theatre and education faculty. The Journal of General Education, 53(3-4), 288-310. https://www.jstor.org/stable/27797997?seq=1

Honey, M., Pearson G., \& Schweingruber, H. (Eds.). (2014). STEM integration in $K-12$ education: Status, prospects, and an agenda for research. National Academies Press. https://doi.org/10.17226/18612

Jang, H. (2016). Identifying 21 st century STEM competencies using workplace data. Journal of Science Education and Technology, 25(2), 284-301. https://doi.org/10.1007/s10956-015-9593-1

Jankovich, J. L., \& Powell, K. S. (1997). An implementation model for a communication across the curriculum program. Business Communication Quarterly, 60(2), 9-19. https://doi.org/10.1177/108056999706000202

Liu, O.L., Frankel, L., Roohr, K.C. (2014). Assessing critical thinking in higher education: Current state and directions for next-generation assessment (ETS Research Report No. RR-14-10). Educational Testing Service. https://doi.org/10.1002/ets2.12009

Lucas, B. (2019). Why we need to stop talking about twenty-first century skills (Seminar Series No. 283). Centre for Strategic Education.

McLeod, S. (2012). The pedagogy of writing across the curriculum. In T. M. Zawacki \& P. M. Rogers (Eds.), Writing across the curriculum: A critical sourcebook (pp. 149-164). Bedford/St. Martin's.

Morgan, M., \& Natt, J. (2013). Effective presentations (3rd ed.). Cengage.

Morton, J., \& O'Brien, D. (2005). Selling your design: Oral communication pedagogy in design education. Communication Education, 54(1), 6-19. https://doi.org/10.1080/03634520500076885 
National Association of Colleges and Employers. (2017). Job outlook 2018 report: The key attributes employers seek on a students' resumes. http://www.naceweb.org/about-us/press/2017/the-key-attributes-employersseek-on-students-resumes/

Northwestern University. (2019a). Design Thinking \& Communication. https://design.northwestern.edu/programs/take-design-course/designthinking-communication/

Northwestern University. (2019b). Design Thinking \& Communication: Curriculum. https://design.northwestern.edu/programs/take-designcourse/design-thinking-communication/curriculum.html

Nowacek, R. S. (2011). Agents of integration: Understanding transfer as a rhetorical act. Southern Illinois University Press.

Orr, C. L. (1996). Communication across the curriculum in animal science. Journal of Animal Science, 74(11), 2828-2834. https://doi.org/10.2527/1996.74112828x

Paretti, M. C. (2008). Teaching communication in capstone design: The role of the instructor in situated learning. Journal of Engineering Education, 97(4), 491-503. https://doi.org/10.1002/j.2168-9830.2008.tb00995.x

Radermacher, A., Walia, G., \& Knudson, D. (2014). Investigating the Skill Gap between Graduating Students and Industry Expectations. In Proceedings from ICSE '14 International Conference on Software Engineering (pp. 291300). Association for Computing Machinery. https://doi.org/10.1145/2591062.2591159

Santos, J. R. A. (1999). Cronbach's alpha: A tool for assessing the reliability of scales. Journal of Extension, 37(2), 1-5.

Sidhu, P., \& Calderon, V. J. (2014, February 26). Many business leaders doubt U.S. colleges prepare students. Gallup. http://news.gallup.com/poll/167630/business-leaders-doubt-collegesprepare-students.aspx

Steinfatt, T. M. (1986). Communication across the curriculum. Communication Quarterly, 34(4), 460-470. https://doi.org/10.1080/01463378609369663

Trilling, B., \& Fadel, C. (2009). 21st century skills: Learning for life in our times. Wiley.

WAC Clearinghouse. (2019a). An introduction to writing across the curriculum: What is writing in the disciplines? https://wac.colostate.edu/resources/wac/intro/wid/

WAC Clearinghouse. (2019b). An introduction to writing across the curriculum: What is writing to learn? https://wac.colostate.edu/resources/wac/intro/wtl/

Winsor, D. A. (1996). Writing like an engineer: A rhetorical education. Erlbaum. 


\section{About the Authors}

Derek Sherman (sherma11@purdue.edu) is a fifth-year PhD student at Purdue University.

Tejasvi Parupudi (tejasvi@utdallas.edu) is a Post-Doctoral Research Associate at The University of Texas at Dallas.

Nathan Mentzer (nmentzer@purdue.edu) is an Associate Professor of Technology and Engineering Education at Purdue University.

Amelia Chesley (amelia.chesley@erau.edu) is an Assistant Professor of Technical and Professional Writing at Embry-Riddle Aeronautical University.

Dawn Laux (dlaux@purdue.edu) is an Associate Clinical Professor of Computer and Information Technology at Purdue University.

Sweta Baniya (baniya@vt.edu) is an Assistant Professor of Rhetoric, Professional, and Technical Writing at Virginia Polytechnic Institute and State University. 